\title{
Conceptualizing the emerging field of smart learning environments
}

Jonathan Michael Spector

Correspondence:

jmspector007@gmail.com

Learning Technologies, University of

North Texas, Denton, TX 76203, USA

\section{Springer}

\begin{abstract}
Learning environments have changed dramatically in the last 50 years, in large part due to information and communications technologies. From the introduction of personal computing and the Internet, there has been a continuing explosion of innovations in support of learning and instruction. Much has been written about new learning approaches and instructional paradigms, but relatively little has been implemented on a large scale with any significant learning outcomes. What has tended to happen when a new learning technology is introduced is that it is tried out on a small-scale in a privileged context (e.g., highly experienced and motivated teachers, on-site researchers, etc.), and when results show promise, the technology is broadly disseminated and used to replace a previous activity or resource, often without adequate training and support. Given the power and potential of new and emerging technologies, it is time to conceptualize how learning environments can be made more effective, efficient and engaging (i.e., smarter) on a large and sustainable scale. This article attempts to provide a small step in that direction.
\end{abstract}

Keywords: Activity systems; Adaptive learning; Epistemology; Human factors; Personalized learning; Psychology of learning

\section{Introduction}

The foundations for the design, development and deployment of learning environments have been drawn somewhat eclectically from such areas as the psychology of learning, instructional design, human-computer interaction, communication theory, cultural anthropology, media research, performance technology, and so on (Richey, Klein, \& Tracey, 2011; Seel, 2012; Spector, 2012). Learning environments specialists have historically been opportunists, adopting and embracing new technologies and creating innovative applications based on what they believed would be effective, efficient, and engaging. However, there has been relatively little strategic thinking about how best to plan and implement learning environments on a large and sustainable scale, and much too little attention to empirical research in this area. Advocacy for a particular approach or technology and emphasis on creativity and innovation have pushed research and theory to the background.

The purpose of this article is to suggest that a convergence of advances and developments in epistemology, psychology, and technology provide a foundation for the planning and implementation of smart learning environments. This foundational framework will be elaborated for multiple contexts with an indication of desirable characteristics specific

(c) 2014 Spector; licensee Springer. This is an Open Access article distributed under the terms of the Creative Commons Attribution License (http://creativecommons.org/licenses/by/4.0), which permits unrestricted use, distribution, and reproduction in any medium, provided the original work is properly credited. 
to representative situations. In addition, an approach for the evaluation of smart learning environments will be provided. First, a few definitions are needed to motivate the discussion.

\section{Definitions}

The recently formed International Association for Smart Learning Environments (IASLE; see http://www.iasle.net/) associated with this journal embraces a broad interpretation of what constitutes a smart learning environment. For example, a learning environment can be considered smart when it makes use of adaptive technologies or when it is designed to include innovative features and capabilities that improve understanding and performance. In a general sense, a smart learning environment is one that is effective, efficient and engaging (Merrill, 2013; Spector \& Merrill, 2008). What is likely to make a learning environment effective, efficient and engaging for a wide variety of learners with different levels of prior knowledge, different backgrounds, and different interests is one that can adapt to the learner and personalize instruction and learning support. This suggests that appropriate adaptation is a hallmark of smart behavior.

The use of 'smart' when applied to a person, while somewhat fuzzy, often implies that the person can adapt in creative and innovative ways to novel or unusual circumstances. The term 'smart' is also attributed to people who are engaged in appropriate planning prior to making a decision or taking an action. Sometimes, the term is applied after seeing the outcome of an action or decision. The adjective 'smart' is used in everyday language to refer to an action or decision that involved careful planning, cleverness, innovation, and/or a desirable outcome (Spector et al., 2012; Spector et al., 2015). People are generally called smart because they are engaged in doing things that are generally effective and efficient. We can also look at how and why people are characterized as not [so] smart, such as when someone simply reacts without reflection, or selects an easy course of action without consideration of alternatives, or when results are undesirable. Non-smart people do not generally engage in doing things that are effective and efficient.

The use of 'smart' in 'smart learning environment' shares some of these attributes. A learning environment that supports planning and innovative alternatives (for the learner or for the instructor) can be considered smart, especially if and when outcomes are desirable. A smart learning environment might include features to promote engagement, effectiveness and efficiency. Such features might include support for (a) collaboration (smart people often seek the advice and guidance of others), (b) struggling learners (smart teachers identify and help struggling students), (c) motivation (smart teachers take the time and make efforts to gain attention, show relevance, and provide feedback to develop confidence and satisfaction). In addition, a learning environment that automatically makes appropriate adjustments to what a learner knows, has mastered, and wants to learn next can be considered smart, just as a person who makes appropriate adjustments to activities and processes given the constraints of a situation or context. Smart people are flexible and adapt to changes as they occur; smart learning environments can do likewise.

The attributes associated with being smart (being adaptive, effective, efficient, engaged, flexible, thoughtful, etc.) will be discussed subsequently as a conceptual model 
for a smart learning environment is developed. There are still the terms 'learning' and 'environment' to consider.

Learning generally involves a stable and persisting change in what a person or group of people know and can do (Spector, 2012). Some learning is planned with specific goals (intentional learning), while other learning is not planned and does not have specific goals (non-intentional or incidental learning). Intentional learning can occur in a formal context (as in school-based lessons with specific goals and objectives) as well as in informal contexts (as in field trips and museum visits with more open-ended goals). Intentional learning is the focus of this discussion, and it is generally considered in the context of more general educational goals, such as developing thoughtful, productive and responsible individuals.

The notion of an environment suggests a place or surroundings in which something occurs. An environment has things that are within the environment and at least roughly defined boundaries. A learning environment might be a classroom with a teacher, students and a variety of tools and technologies to support learning; it could be a computer workstation at home, at school or in the workplace, in which case there are also other things in the environment to take into account, some of which might be distractions. A learning environment might be partly virtual, as in a highly interactive simulation or immersive 3D learning place. Whether physical or virtual, an environment can be conducive to or inhibitive of learning. A smart learning environment, in keeping with the emphasis on efficacy, is one that is generally conducive to and supportive of learning.

\section{Considering the foundations}

Thus far, the discussion has been aimed at indicating how the phrase 'smart learning environment' can be parsed in terms of how the constituent terms are typically used. The basic notion is that there is a sense of what a smart learning environment is, just as there is a general understanding of what a smart person is. An important difference, though, is that learning environments are designed, whereas people develop (understanding, intelligence and ability), or, in some cases and situations, they fail to do so.

The challenge, then, is to develop a reliable framework to guide the design, development and deployment of smart learning environments. What has been happening in too many cases is that those who become enthralled with a new technology take what they like and might have learned from coincidence and proceed with implementing various learning environments, many of which are innovative, some of which might be somewhat effective, and few of which can be replicated in a different context or taken to scale. Hopefully, a framework based on theory, research and prior development work will help in that regard.

\section{Three foundation areas}

There are at least three foundation areas that provide meaningful and convergent input for the design, development and deployment of smart learning environments: epistemology, psychology and technology. Each of these is elaborated next.

\section{Epistemology}

At a high level, philosophy, especially epistemology, provides a coherent approach to many human activities, including instructional design and technology research and 
practice. The relevant philosophical perspective that informs smart learning environments and other areas of learning and instruction is naturalistic epistemological. In the world of education, that perspective is more commonly referred to as social constructivism. It consists of two primary tenets that describe how humans develop knowledge and expertise.

The first tenet involves the creation of mental models when encountering new or unusual or otherwise unexplained experiences. Simply stated, this is the notion that people create internal representations to make sense of their experience. This principle can be found in Wittgenstein's Tractatus Logico-Tractatus in statement 2.1: "We picture facts to ourselves" (Wittgenstein, 1961, p. 8). Within the area of education, David Jonassen and others have use the term 'constructivism' to refer to a description of the way that people develop knowledge in the form of meaning-making activities (see, for example, Jonassen, 1991). This perspective puts the individual at the center of knowledge and skill development, and it implies that individuals may develop knowledge and skills differently. Individual characteristics, especially prior experience and knowledge, then become major factors in planning and supporting learning.

The second tenet from a philosophical perspective involves the role of language as a critical mediator in learning and knowledge development. In Wittgenstein's (1953; published posthousmly) Philosophical Investigations, the notion of language games was introduced and discussed at length. In that work, Wittgenstein describes the very human activity of engaging in discourse in a way that follows relatively local rules and protocols, which were called a language game. The underlying idea is that interaction with others, especially in the form of discourse, contributes to how knowledge is developed. A great deal of learning is in fact language-mediated and language-dependent.

Taken together, these two tenets provide a general description of how people come to know and understand their worlds - namely by a process of creating internal mental representations and then sharing ideas formed on the basis of those representations with others through appropriate languages and media. That is to say that social constructivism is grounded quite firmly in a naturalistic epistemological perspective that is widely accepted by philosophers as well as by psychologists and educational researchers. Because social constructivism provides a coherent philosophical foundation for learning and instruction, it should be recognized as a pillar of any smart learning environment.

\section{Psychology}

The role of psychology in learning and instruction is well recognized. The two main streams of educational psychology have been behaviorism and cognitivism. Both have a place in more recent psychological explorations that include non-cognitive processes as well as group processes that impact learning. Because psychology is conceptualized as a scientific enterprise, it quite naturally attempts to describe as well as explain human activities. There is value in each of various psychological disciplines mentioned above, and a smart learning environment might well incorporate aspects of each.

Behaviorism emphasizes things that can be observed and measured as a way to understand and predict human behavior (see, for example, Watson, 1913). A radical form of behaviorism implied the non-existence or at least the non-relevance of things that could not be observed and measured in some way. While that form of behaviorism 
has fallen into disrepute among psychologists and educational researchers, the value of observable outcomes remains a valuable and productive aspect of educational science. Outcomes are now measured both directly and indirectly, and the value of qualitative methods and data as well as quantitative methods and data in understanding outcomes is now widely accepted. Nonetheless, the emphasis on outcomes is a valuable contribution of behaviorism that is worth retaining in understanding smart learning environments.

Cognitivism emphasizes the need to understand mental processes that underlie and can explain many human behaviors (see, for example, Ebbinghaus, 1885). The role of memory and perceptual effects led to a great many studies that eventually adopted a mental processing model similar to that used in computer science. Computer scientists who became interested in modeling human cognition developed a discipline typically referred to as cognitive science (see, for example, Anderson, 1983). The contributions of cognitive scientists have continued to expand how computers can be used to model and support human learning in the form of intelligent tutoring systems and pedagogical agents. The lessons learned from these efforts should inform the planning and implementation of smart learning environments.

A third psychological perspective places emphasis on group and social activities. Social psychology emphasizes the effects and impact of others on how people think and behave (see, for example, Lewin et al. 1939). There is a strong parallel between social psychology and its relationship to behavioral and cognitive psychology and the relationship between the two philosophical tenets discussed previously. People do not live and learn in isolation from others. A smart learning environment will take this fact into account explicitly and in meaningful ways.

A fourth psychological perspective places emphasis on non-cognitive aspects of human thought and behavior. There are many non-cognitive aspects that psychologists have investigated, including emotions, habits, and the chronology of experienced events. This area reflects the implicit admission of psychologists that human thought and action are quite complex and not fully explained in terms of behavior or cognition, and, as a consequence, not easily modelled by cognitive scientists. Nonetheless, there are ways that humans have taken non-cognitive aspects of thought and behavior into account in their interactions with others. Parents do this quite often and occasionally with success with their children. For example, a parent may recognize a child's actingout behavior as a result of an emotional state connected with an entirely unrelated prior event. There are now pedagogical agents that adopt indirect methods to address such concerns in a learning context (see, for example, Kim, 2012), and these should definitely be considered a characteristic of a smart learning environment.

\section{Technology}

Technology is the systematic application of knowledge to achieve a purpose valued by a group or a society. Technologies have changed dramatically in the last 100 years (see, for example, Spector \& Ren, in press). Modern information and communications technologies provide a significant challenge for the design, development, and deployment of learning environments, instructional systems and performance technologies. Which technologies should be used to support which goals and objectives for different learners in a variety of situations? Which ones are likely to be effective and sustainable? Finally, which ones will contribute to the development of smart learning environments? 
Recalling the informal use of 'smart' described earlier, one might say that a technology is smart if and when it is effective, efficient, innovative, engaging, flexible, and so on. A smart educational technology is one that accomplishes its purpose effectively and efficiently. This often requires an innovative use of a technology in an engaging and flexible manner. As it happens, the word 'smart' is now attached to a number of educational technologies that do not have very many (or any) of those characteristics. One finds the phrase 'smart phone' and 'smart board' in widespread use in educational technology. Whiles these can be considered innovative technologies, their use in education is typically not very innovative, and they fail to have many other characteristics of smartness.

They do have the potential to become smarter, however. For example, smart phones can already track a person's location and keep a history of that person's purchases. When that person is in a store, a smart phone could conceivably send a message to the person noting that a particular item of likely interest is on sale in that store. Such an action would represent a flexible and engaging application - albeit not particularly educational. A smart board could capture a child's picture or fingerprint; it could also have a database of the pictures or fingerprints of the children in the class along with a history of the performance and problems each child has exhibited. Then, after a child attempts to solve a complex or challenging problem, the smart board could offer a suggestion to guide the child to a correct solution; or the smart board could simply ask the child to respond to a question that is likely to cause a revision in the child's response. Such a smart board could then be genuinely considered smart.

\section{Towards a framework for smart learning environments}

A naturalistic approach to epistemology that focuses on a description of how people actually develop knowledge concludes that there is no single or simple way to characterize knowledge development. People create internal representations and then talk about those representations with others along various paths to understanding. People are smart in different ways, at different times, and in different circumstances. However, it is clear that the ability to engage in meaningful discourse with others facilitates the development of knowledge.

Various psychology approaches to human thought and action provide descriptions of a variety of processes and factors that affect thought and action. The varieties of learning experiences are many, even for one person or for a specific group of people. However, it is again clear that providing personalized feedback and supporting collaboration with others can result in desired outcomes, while ignoring social and affective factors can inhibit learning.

The lessons learned from educational technology are many and varied. Simply using a new technology to replace prior practice may not be an effective use of an innovative technology. Because a technology is innovative does not mean that its use to support learning and instruction will be innovative or effective. What we can take from prior educational technology applications is that early successes in small and privileged settings can be misleading; taking an educational technology to scale involves significant planning, policy [re-]development, training, support and leadership that are all too often lacking in educational systems. 
What do these perspectives provide with regard to a framework for smart learning environments? Perhaps there are a few characteristics from these foundational perspectives that can be extracted and used as a preliminary set of indicators of the smartness of a learning environment. In any case, here is a preliminary and partial set of characteristics for a smart learning environment, divided into three categories.

\section{Necessary}

a Effectiveness - the learning environment results in generally acceptable or desirable learning outcomes, preferably better than a corresponding non-smart learning environment with similar learners.

b Efficiency - the learning environment is cost effective, preferably not costing significantly more in initial capital expenditure, support and maintenance over a five-year period than a non-smart learning environment with a similar number of learners.

c Scalable - the learning environment has been demonstrated to be effective and efficient on a large scale that extends well beyond one case or a small number of limited and restricted tryouts.

d Autonomous - the learning environment can react appropriately and autonomously to different learning situations and circumstances, as would a human teacher or tutor; this includes the ability to help learners become more organized and aware of their own learning goals, processes and outcomes.

\section{Highly desirable}

a Engaging - the learning environment is capable of motivating and sustaining continuing interest and participation of a variety of learners, preferably more so than in a corresponding non-smart learning environment.

b Flexible - the learning environment can adjust to changes, such as new learners joining the course, different resources being introduced, or additional goals or objectives being added.

c Adaptive - the learning environment can adjust to specific learner needs by recognizing learners' competencies, learning styles, and interests (see, for example, Kumar, Graf, \& Kinshuk, 2011).

d Personalized - the learning environment can provide personalized assignments and/or formative feedback just when needed to help struggling learners as well as those progressing rapidly.

\section{Likely}

a Conversational - the learning environment can engage the learner in a dialogue or facilitate a group dialogue on a relevant topic or problem.

b Reflective - the learning environment can generate a self-assessment based on student progress and performance, preferably suggesting activities and attributes in the learning environment that can be adjusted to improve overall effectiveness. 
c Innovative - the learning environment makes use of new and emerging technologies, and uses innovative technologies in innovative ways to support learning and instruction.

d Self-organizing - the learning environment can rearrange resources and control mechanisms to improve its performance over time based on data that are automatically collected and used to refine how the environment interacts with learners in various circumstances.

The intention is to provide a rough way to operationalize each characteristic and to suggest that it is appropriate to obtain measures of outcomes and performance against non-smart learning environments that might be replaced in some cases. Having multiple categories suggests that each characteristic might be weighted according to the appropriate category, although there should be some characteristics that all smart learning environments must meet.

It is probable that others will identify different categories and characteristics or perhaps add to this partial list. In any case, it is intended only as a first step towards a framework for the emerging field of smart learning environments (see Figure 1).

In order to support the progressive development and refinement of smart learning environments, there should be ongoing evaluations. These evaluations include both formative and summative aspects. On the formative evaluation side, regular and systematic collection and analysis of student and instructor expectations, perceptions and reactions should be conducted. Of particular interest on the formative side is how expectations and perceptions changed over time. Such information can be collected using surveys, interviews and focus groups. Asking those who use the environment to identify strengths as well as weaknesses or areas that caused difficulty or problems is especially

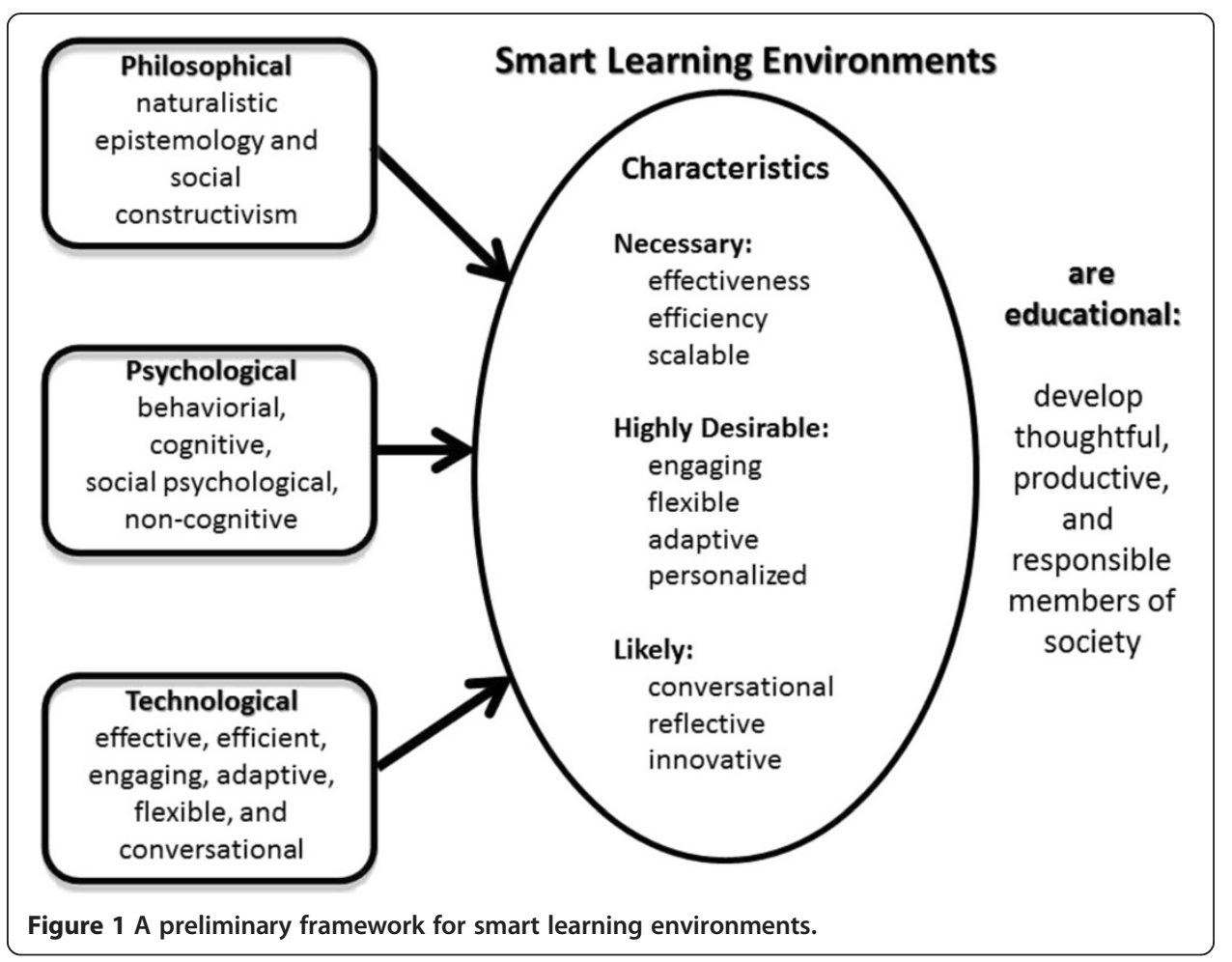


important in a formative evaluation process. With regard to summative evaluation, student performance data are especially important as those data speak directly to two of the necessary characteristics identified in the framework: effectiveness and efficiency. Together with the formative evaluation data that are collected, the scalability and autonomy of the learning environment can also be determined. The general evaluation approach is to link data collected and analyzed to critical characteristics of the learning environment. Having a baseline comparison group or a control group for evaluation purposes is highly desirable but typically difficult to implement.

\section{Conclusion}

The general claim is that the extent to which these characteristics are present will determine whether and to what extent a particular learning environment should be considered smart. The hope is that having such a set of characteristics will keep the word 'smart' from being abused and misused in connection with learning environments as it has been misused and abused in connection with technologies such as mobile phones and whiteboards. The driving desire behind the smart learning environments movement is to transform learning and instruction in productive and desirable ways. To accomplish this, it is important to recognize that an applied science enterprise such as educational research, especially as it applies to smart learning environments, should adopt basic principles and approaches that can be measured, refined, and in some cases abandoned. To make systematic progress, more than advocacy for adopting something new is required. What is required is the smartness that educational technologists are now designing into learning environments: effectiveness (an ability to achieve recognized goals and objectives), efficiency (the ability to be effective without exorbitant costs and extreme effort), engagement (the willingness to collaborate with and learn from others), flexibility (the willingness to try new things), adaptivity (the ability to adjust to different situations and make appropriate adjustments), and reflectiveness (the ability to recognize successes and failures and learn from mistakes).

Received: 16 February 2014 Accepted: 9 May 2014

Published: 16 October 2014

References

JR Anderson, The architecture of cognition (Harvard University Press, Cambridge, MA, 1983)

Ebbinghaus, Über das Gedächtnis (On memory; H. Ruger \& C. Bussenius, Trans) (Teachers College, New York, 1885)

DH Jonassen, Objectivism vs. constructivism. Educational Technology Research \& Development 39(3), 5-14 (1991)

$\mathrm{C}$ Kim, The role of affective and motivational factors in designing personalized learning environments. Educational Technology Research \& Development 60(4), 563-584 (2012)

$\checkmark$ Kumar, S Graf, Kinshuk, Causal competencies and learning styles: A framework for adaptive instruction. Journal of e-Learning and Knowledge Society 7(3), 13-31 (2011)

K Lewin, R Lippitt, RK White, Patterns of aggressive behavior in experimentally created social climates. Journal of Social Psychology 10, 271-301 (1939)

MD Merrill, First principles of instruction: Identifying and designing effective, efficient and engaging instruction (Wiley, San Francisco, CA, 2013)

RC Richey, JD Klein, MW Tracey, The instructional design knowledge base: Theory, research, and practice (Routledge, New York, 2011)

NM Seel (ed.), The encyclopedia of the sciences of learning (Springer, New York, 2012)

JM Spector, Foundations of educational technology: Integrative approaches and interdisciplinary perspectives (Routledge, New York, 2012)

JM Spector, D Ifenthaler, TE Johnson, WC Savenye, MM Wang (eds.), Encyclopedia of educational technology (Sage, Thousand Oaks, CA, 2015)

JM Spector, MD Merrill (eds.), Special issue: Effective, efficient and engaging $\left(E^{3}\right)$ learning in the digital age. Distance Education, 2008. 29(2)

JM Spector, MD Merrill, J Elen, MJ Bishop (eds.), Handbook of research on educational communications and technology 4th edn. (Springer, New York, 2012) 
JM Spector, Y Ren, History of educational technology, in Encyclopedia of Educational Technology, ed. by JM Spector, D Ifenthaler, TE Johnson, WC Savenye, MM Wang (Sage, Thousand Oaks, CA, in press)

J Watson, Psychology as a behaviorist views it. Psychological Review 45, 1-41 (1913)

L Wittgenstein, Philosphical investigations. (G. E. M. Anscombe, Trans.) (Blackwell, Oxford, UK, 1953)

L Wittgenstein, Tractatus logico-philosophicus (D. F. Pears \& B. F. McGuiness, Trans.; first published in German in 1921) (Humanities Press, New York, 1961)

doi:10.1186/s40561-014-0002-7

Cite this article as: Spector: Conceptualizing the emerging field of smart learning environments. Smart Learning Environments 2014 1:2.

Submit your manuscript to a SpringerOpen ${ }^{\circ}$ journal and benefit from:

- Convenient online submission

- Rigorous peer review

- Immediate publication on acceptance

Open access: articles freely available online

- High visibility within the field

- Retaining the copyright to your article 